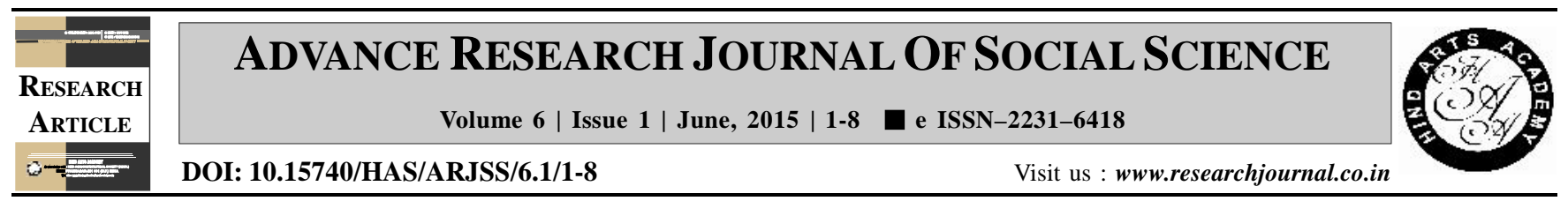

\title{
A study on emotional intelligence of adolescents
}

Jinamoni Saikia*, Anshu ${ }^{1}$ and Anjali Mathur ${ }^{1}$

Department of Human Development and Family Studies, College of Home Science, Assam Agricultural University, JORHAT (ASSAM) INDIA

(Email: jina_saikia@yahoo.com)

${ }^{1}$ Department of Human Development and Family Studies, Halina School of Home Science, Sam Higginbottom Institute of Agriculture, Technology and Sciences, ALLAHABAD (U.P.) INDIA

\section{ARTICLE INFO :}

$\begin{array}{lll}\text { Received } & : & 19.11 .2014 \\ \text { Revised } & : & 01.04 .2015 \\ \text { Accepted } & : & 10.04 .2015\end{array}$

KEY WORDS :

Emotional intelligence, Adolescents, Socioculture

\section{HOW TO CITE THIS ARTICLE :}

Saikia, Jinamoni, Anshu and Mathur, Anjali (2015). A study on emotional intelligence of adolescents. Adv. Res. J. Soc. Sci., 6 (1) : 1-8.

*Author for correspondence

\begin{abstract}
The present study was taken up to find out the emotional intelligence levels of adolescents and to find out the differences among them due to different sociocultural background. The sample size comprised of 325 adolescents (16-18 years) drawn from urban, rural and tribal areas of Jorhat district of Assam. It can be highlighted from the results that the level of emotional intelligence of most of the adolescents was far better in the dimension of interpersonal management.Majority of adolescents were least competent in the abilities pertaining to the dimension of intrapersonal management. Majority of adolescents of urban culture were found to have more skills in all the dimensions of emotional intelligence than the adolescents of rural culture barring interpersonal management. The adolescents of tribal culture possessed considerably low level in all the dimensions of emotional intelligence.
\end{abstract}

